\title{
Enfermedades Diarreicas Agudas asociadas a Rotavirus
}

\author{
CARLA ROMERO ${ }^{1}$, NATANIEL MAMANI ${ }^{1}$, KJETIL HALVORSEN $^{2}$ VOLGA IÑIGUEZ ${ }^{3}$
}

1. Lic. Biología. Instituto de Biología Molecular y Biotecnología, Unidad de Biología Molecular de Enteropatógenos, Carrera de Biología, Facultad de Ciencias Puras y Naturales. Universidad Mayor de San Andrés.

2. Lic. en Estadística. Unidad de Biología Molecular de Enteropatógenos, Carrera de Biología, Facultad de Ciencias Puras y Naturales. Universidad Mayor de San Andrés.

3. Ph.D. Biología. Unidad de Biología Molecular de Enteropatógenos, Carrera de Biología, Facultad de Ciencias Puras y Naturales. Universidad Mayor de San Andrés.

\begin{abstract}
Acute diarrhea diseases associated to Rotavirus

In the period of 2001-2002, a total of 1163 fecal samples were collected from children less than five years of age with diarrhea, at the Hospital Albina Patiño and other health centers in Cochabamba city. Rotavirus infection general prevalence was $19 \%$ (220), distributed among hospitalized children $24 \%$ (77) and outpatients $17 \%$ (143). Rotavirus infections were observed along the whole study period, with highest prevalence in coldest months: April (24\%), May (34\%) and June (28\%) and lowest frequencies (8-15\%) in February, August, and September. Major rotavirus outbreak was significantly associated with the driest and colder season. The highest percentage of rotavirus infections $(36,3 \%)$ was found among children between 7-12 months of age. Moderate dehydration, vomits and fever were the clinical symptoms more frequently associated with rotavirus acute gastroenteritis, being dehydration more common in hospitalized patients. The distribution of P and G genotypes analyzed by RT-PCR was: G1 (44\%), G2 (6\%), P[8] (24\%) and P4 (15\%). A co-infection P[8]P[6] was observed in 3 samples (4\%). Genotype P[6] was found associated to outpatients. These findings, highlight that rotavirus is an important cause of acute gastroenteritis and that any of the currently available vaccines would potentially be protective against circulating strains found in the city of Cochabamba.

(Key words: acute diarrheal diseases, rotavirus, G and P genotypes, RT-PCR).

Rev Soc Bol Ped 2005; 44 (2): 75-82
\end{abstract}

\section{RESUMEN}

Un total de 1163 muestras de heces, fueron recolectadas de niños con enfermedades diarreicas agudas (EDA) menores a 5 años del Hospital Albina Patiño y otros centros de salud de la ciudad de Cochabamba en el período 2001-2002. La infección por Rotavirus presentó una prevalencia general del 19\% (220)

Artículo recibido 10/7/05, fue aprobado para publicación 2/9/05. 
presentándose en un 24\% en pacientes hospitalizados y en el 17\% (143) en ambulatorios. Las infecciones por rotavirus se presentaron a lo largo de todo el período de estudio, las frecuencias mas altas de infección se observaron en los meses de invierno, abril (24\%), mayo (34\%) y junio (28\%) y las más bajas (8-15\%) en los meses de febrero, agosto y septiembre. El análisis de asociación de la infección por rotavirus, con parámetros climáticos, mostró que los picos más altos de infección, correlacionan con la época mas seca y fría. El mayor número de casos de infección por rotavirus se presentó en niños entre 7-12 meses de edad (36,3\%). Los síntomas clínicos más comúnmente asociados a la diarrea rotaviral fueron: la deshidratación moderada, seguida de vómitos, y fiebre, siendo la primera más frecuente en pacientes hospitalizados que ambulatorios. El análisis de la distribución de genotipos G y P mediante el ensayo de reverso trascripción (RT-PCR), reveló la presencia de los genotipos G1 (44\%), G2 (6\%) y P[8] (24\%), P[6] (15\%). Se observó una coinfección $\mathrm{P}[8] \mathrm{P}[6]$ en tres muestras $(4 \%)$ y asociación del genotipo $\mathrm{P}[6]$ con los casos de procedencia ambulatoria. En conjunto, estos hallazgos resaltan la importancia del rotavirus como causa de las EDA y permiten inferir que las acunas anti-rotavirales actualmente vigentes, brindarían protección contra las cepas circulantes encontradas en la ciudad de Cochabamba.

(Palabras clave: enfermedades diarreicas agudas, rotavirus, genotipo G y P, RT-PCR).

Rev Soc Bol Ped 2005; 44 (2): 75-82

\section{Introducción}

Mundialmente las enfermedades diarreicas agudas (EDA) son la causa más común de morbi-mortalidad infantil siendo responsables de 2 millones de muertes anualmente en niños menores a 5 años, lo que equivale entre 1400 a 1900 episodios de diarrea y 5 muertes por minuto $^{1,2}$.

En Bolivia, las EDA se presentan en alrededor del $30 \%$ de la población total de niños menores a 5 años $^{3}$, produciéndose anualmente más de 12000 muertes. En la ciudad de Cochabamba similar a otras regiones de Bolivia, las EDA son una de las principales causas de consulta y hospitalización en la población infantil. Así, en el año 2002 se registraron casos de diarreas en el $36 \%$ de los niños menores a 5 años y 1395 hospitalizaciones por esta causa ${ }^{3}$.

Entre los patógenos asociados a la diarrea, los rotavirus humanos representan la causa más común de gastroenteritis infantil en todo el mundo. Se ha estimado que anualmente causan 111 millones de episodios diarreicos en pacientes ambulatorios, 2 millones de hospitalizaciones y entre 352000 a 592000 muertes en niños menores a 5 años. Hasta los 5 años de edad, todos los niños han tenido por lo menos un episodio de gastroenteritis causada por rotavirus, estimándose que 1205 niños mueren diariamente a causa de éste virus, más del $82 \%$ de los cuales provienen de países pobres ${ }^{4,5}$.
Los rotavirus son miembros de la familia Reoviridae, presentan un genoma que consiste de 11 segmentos de RNA de doble cadena (RNAdc), y tres capas concéntricas de proteínas que engloban al genoma viral. Estos virus están clasificados en grupos, subgrupos y serotipos de acuerdo a propiedades de las proteínas de la cápside. La clasificación en serotipos esta basada sobre las diferencias antigénicas y producción de anticuerpos neutralizantes de las proteínas VP7 y VP4 de la cápside externa. VP7 es una glicoproteína codificada por el gen 9 que determina la especificidad del serotipo específico G. VP4, es a su vez, una proteína codificada por el gen 4, que determina el genogrupo $\mathrm{P}^{6,7}$. VP7 y VP4 inducen respuesta inmunológica serotipo-especifica (homotípica), además de reacción cruzada (heterotípica) ${ }^{8}$.

Existe alta diversidad de serotipos G y P en humanos y animales que comprende al menos 15 tipos $\mathrm{G}^{9}$ y 20 tipos $\mathrm{P}^{10,11}$. Los serotipos $\mathrm{G} 1$ a G4 son los más prevalentes en humanos, lo mismo que los genogrupos $\mathrm{P}[8]$ y $\mathrm{P}[4]^{12}$. La genotipificación de las proteínas de la cáspside externa del rotavirus es importante para definir la diversidad de cepas circulantes en una región determinada, previa y posteriormente a la introducción de una vacuna.

Actualmente, dos vacunas contra rotavirus: Rotarix y Rotateq están registrando su licencia en varios países, después de haber sido analizadas en pruebas de fase 3 en alrededor de 
70000 niños: Rotarix ${ }^{\mathrm{TM}}$ (GSK) vacuna monovalente humana y Rotateq $^{\mathrm{TM}}$ (Merck), vacuna pentavalente bovina-humana.

Por la alta prevalencia de las EDA en Bolivia y al ser este un país elegible para el apoyo de la Alianza Global para la Vacunación e Inmunización (GAVI), es imperante generar información sobre la diarrea asociada a rotavirus en diferentes regiones geográficas. En este sentido, este trabajo representa un aporte al conocimiento de la diarrea rotaviral en la ciudad de Cochabamba, por una parte respecto a su epidemiología y por otra, en cuanto a la caracterización molecular de cepas de rotavirus circulantes.

\section{Material y Métodos}

Definición de caso. Se incluyeron al estudio 1163 niños menores a 5 años (hospitalizados o que acudieron a consulta externa al hospital) con diarrea aguda, definida como 3 ó más evacuaciones líquidas o semilíquidas en las últimas 24 horas (OMS) en el período de octubre del 2001 a octubre del 2002.

Recolección de muestras. Las muestras diarreicas se recolectaron de 1042 pacientes del Hospital Albina Patiño y 121 pacientes de diferentes centros de salud y clínicas privadas.

Una vez recolectadas, las mismas fueron conservadas a $-20^{\circ} \mathrm{C}$ hasta su traslado para el diagnóstico y caracterización molecular en el Instituto de Biología Molecular y Biotecnología de la Carrera de Biología de la Universidad Mayor de San Andrés de la ciudad de La Paz.

Extracción y PAGE del RNA viral. Un volumen de 100 ul de muestra fue suspendido en 200 ul de solución de lisis (SDS 0,5\%; Acetato de $\mathrm{Na} 0,1 \mathrm{M}$; Beta-mercapto-etanol 0,25\%; Tritón 1\%), seguido de la adición de 200 ul de Fenol/Cloroformo. La suspensión fue precipitada por centrifugación (12000 g/5 min). Posterior a la extracción, el RNA viral fue separado en geles de Poliacrilamida al 7\% (Acrilamida $30 \%$ y Bis-acrilamida $0,8 \%$ ) a 30 voltios, durante 12 horas a temperatura ambiente y visualizado con tinción de nitrato de plata ${ }^{13}$.

Genotipificación por reverso trascripción mediante RT-PCR. La purificación del RNAdc ${ }^{14}$ se llevó a cabo a partir de 10 a 20 ul de muestra. Posteriormente, se realizó el ensayo de RT-PCR para los genotipos G y P, acorde al protocolo descrito por Gouvea y col (1990 \& 1994) y Gentsch y col (1992).

Recolección de Datos. La información clínica epidemiológica del estudio se recolecto a través de una ficha que incluía por una parte, datos de los pacientes del estudio, en cuanto a: sexo, fecha de admisión y por otra, manifestaciones clínicas, grado de deshidratación, tratamiento recibido y enfermedades intercurrentes.

Los datos climáticos fueron proporcionados por AASANA Cochabamba, correspondientes a la gestión de estudio.

Análisis estadístico. Se realizó análisis univariado, a través de tablas de contingencia y pruebas de $\chi^{2}$. La asociación del rotavirus con parámetros climáticos, fue complementada con modelos simples de regresión logística y regresión logística aditiva. Todos los análisis fueron realizados en el paquete estadístico $\mathrm{R}$ de libre acceso $\left(\right.$ Licencia $\left.\mathrm{GPL}_{2}\right){ }^{17}$

\section{Resultados}

El $90 \%$ de las muestras recolectadas provienen del Hospital pediátrico Albina Patiño, considerado un hospital de tercer nivel en el departamento de Cochabamba, mientras que el $10 \%$ restante proviene de diferentes centros de salud y clínicas privadas (Posta zona sud, Centro de salud Tiquipaya y Clínica Belga).

El porcentaje de muestras recolectadas mensualmente del Hospital Albina Patiño en promedio corresponde a un $60 \%$ y $18 \%$ del total de casos hospitalizados y ambulatorios respectivamente (figuras $1 \mathrm{a}$ y $1 \mathrm{~b}$ ).

La presencia de rotavirus, se analizó por electroforesis del RNA viral en geles de poliacrilamida (PAGE) en el total de muestras fecales, provenientes de pacientes ambulatorios y hospitalizados. El total de muestras positivas para rotavirus corresponde a electroferotipos de patrón largo (figura 2).

La prevalencia de infección por rotavirus en la población estudiada fue de 19\% (220) encontrándose diferencias estadísticamente significativas $(\mathrm{p}<0,005)$ entre pacientes hospitalizados (24\%) y ambulatorios (17\%) (tabla 1$)$. 


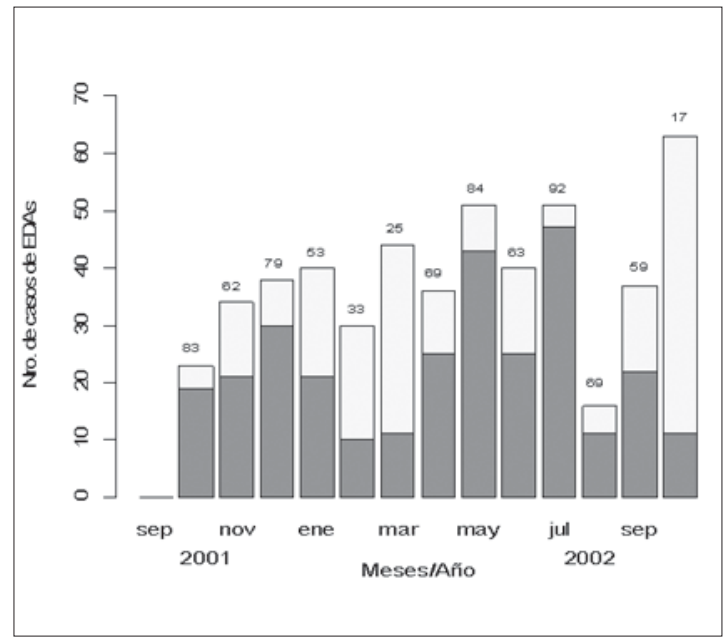

Figura 1a. Distribución mensual del porcentaje de casos analizados (rojo) en relación al número total de casos de EDA (amarillo) registrados en pacientes hospitalizados.

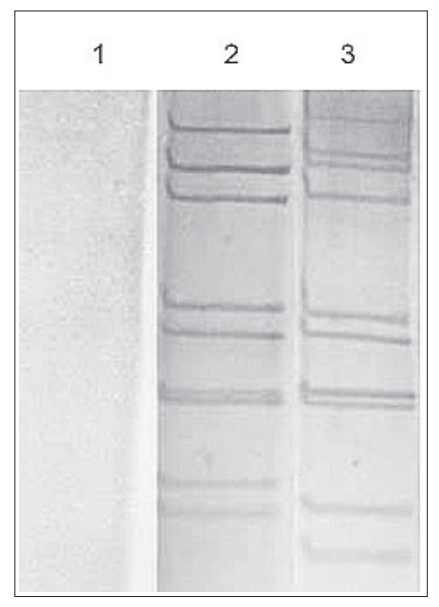

Figura 2. Electroforesis del genoma de Rotavirus (Rv), visualizado en un gel de poliacrilamida (PAGE) con tinción de nitrato de plata. Se observan los 11 segmentos del RNAdc, Carriles: 1, muestra control Rv (-); 2, muestra control Rv $(+)$; 3, muestra control Rv $(+)$ de electroferotipo largo

El análisis de distribución mensual de la infección por rotavirus reveló la presencia del virus durante todos los meses a lo largo del año con una variación desde un $8 \%$ hasta un 34\% $\left(\chi_{13}^{2}=41,31 ; p<0,0005\right)$. Las frecuencias más altas de infección por rotavirus, se presentaron en el período de invierno que corresponde a los meses de abril (24\%), mayo (34\%) y junio

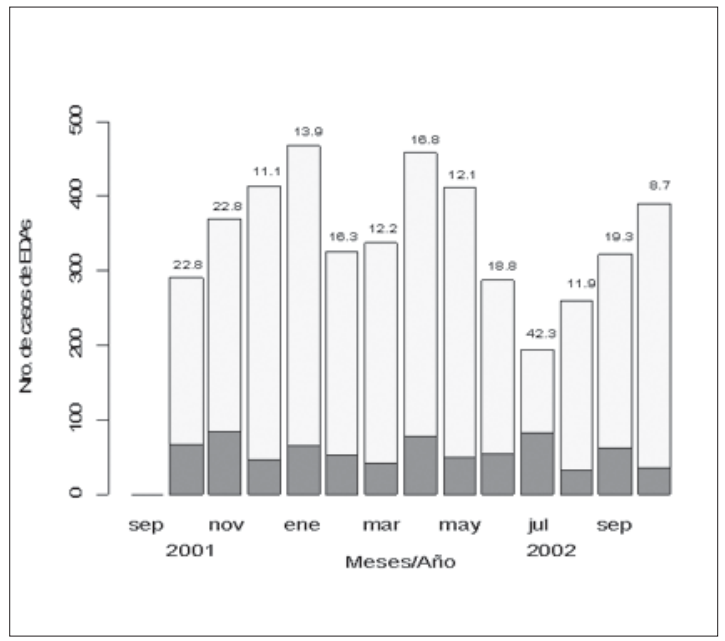

Figura 1b. Distribución mensual del porcentaje de casos analizados (rojo) en relación al número total de casos de EDA (amarillo) registrados en pacientes ambulatorios.

Tabla 1. Número y porcentaje de casos de diarreas por rotavirus que se registraron en la ciudad de Cochabamba durante el período 2001-2002

\begin{tabular}{lccrc}
\hline Procedencia & \multicolumn{2}{c}{$\begin{array}{c}\text { Casos } \\
\text { analizados } \\
\mathbf{n}\end{array}$} & $\begin{array}{c}\text { Casos } \\
\text { (\%) }\end{array}$ & $\begin{array}{c}\text { rotavirus positivo } \\
\mathbf{n}\end{array}$ \\
\hline (\%)
\end{tabular}

$\left(\chi_{1}^{2}=7,73 ; p<0,005\right)$

(28\%), por otro lado las frecuencias más bajas se registraron en los meses de febrero (9\%), marzo (11\%) y septiembre ( $8 \%$ ) (figura 3$)$. La correlación de la diarrea rotaviral respecto a la distribución de casos de EDA registrados en el Hospital Albina Patiño, mostró que el brote de EDA registrado entre abril y junio coincide con los mayores porcentajes de diarrea rotaviral.

El grupo etáreo entre 7-12 meses de edad, fue el que presento mayor número de casos de infección por rotavirus $(36,3 \%)$ en el total de muestras analizadas (Figura 4). El porcentaje acumulativo de la infección por rotavirus mostró que hasta los 12 meses de edad, el $50 \%$ de la población estudiada, presentó esta infección. De 
forma similar el $90 \%$ de la población de niños entre los 24 y 48 meses de edad, fue infectada por rotavirus (figura 5). En pacientes hospitalizados, los porcentajes más altos de infección por rotavirus se registraron en niños entre los 3-24 meses de edad y en pacientes ambulatorios tanto en niños

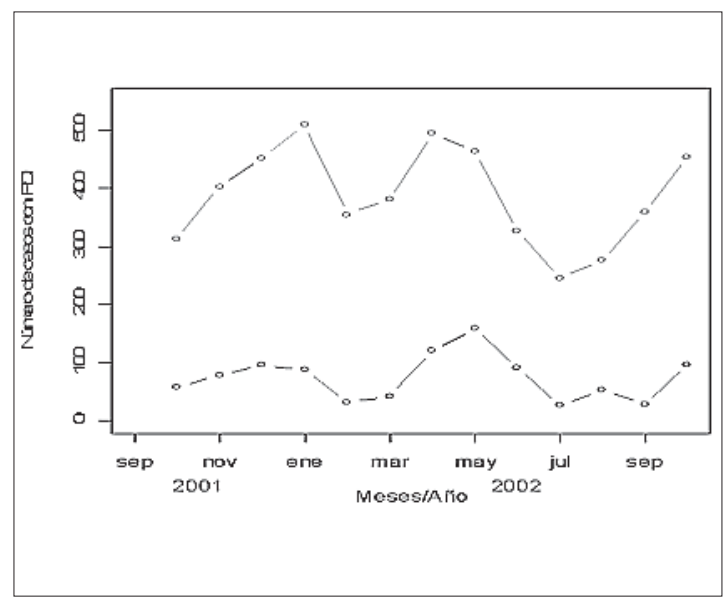

Figura 3. Distribución mensual de EDA e infecciones por rotavirus. Distribución mensual del número de casos con Procesos Diarreicos Infecciosos (PDI) (rojo) y número de casos de diarreas causadas por Rotavirus (azul).

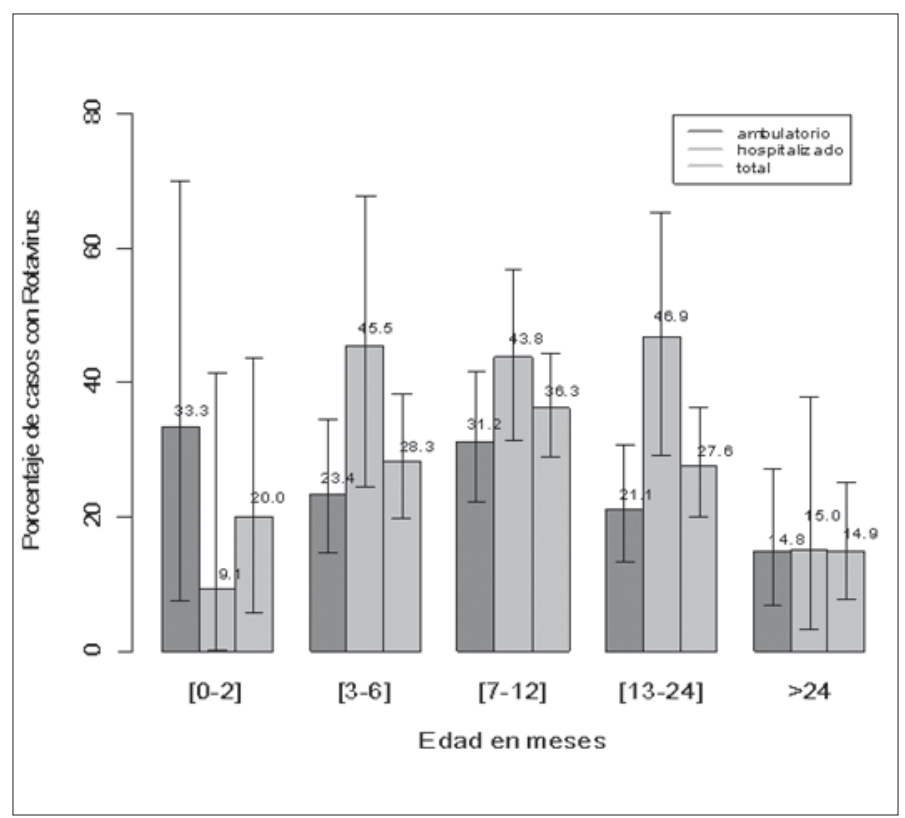

Figura 4. Distribución de los casos de infección por rotavirus en función a grupos etáreos (naranja) en pacientes hospitalizados (rojo) y pacientes ambulatorios (celeste). menores a 2 meses como en niños de 7-12 meses de edad (figura 4).

Los síntomas clínicos más frecuentemente asociados a la diarrea rotaviral fueron: la deshidratación moderada, seguida de vómitos y fiebre. La deshidratación moderada presentó los mayores porcentajes de sensibilidad (66\%), confiabilidad $(83 \%)$, valor predictivo positivo (VPP) $(83 \%)$ y valor predictivo negativo (VPN) (94\%) (tabla 2). Asimismo el $71 \%$ de los pacientes hospitalizados presentó, un grado de deshidratación moderada, en contraste al porcentaje observado en pacientes ambulatorios $(28 \%)\left(\chi^{2}{ }_{2}=\right.$ $31,9 ; \mathrm{p}<0,0001)$.

El análisis, de la relación entre la diarrea rotaviral con otras enfermedades intercurrentes se presenta en la tabla 3. Se encontró que el $22 \%$ de los casos rotavirus-positivo, presentaron al mismo tiempo, infecciones causadas por amebas y parásitos, en contraste a un $43 \%$ de pacientes negativos a rotavirus, que presentaron diarreas parasitarias $\left(\chi^{2}{ }_{1}=11,36 ; p<0,0005\right)$. Asimismo, se observó diferencias (aunque no significativas) en el $15 \%$ y $25 \%$ de casos positivos a rotavirus que presentaron IRAs y anemia, siendo estos valores mayores que los encontrados en pacientes sin infección rotaviral en un $8 \%$ y $16 \%$ respectivamente (tabla 3 ).

Entre los tratamientos administrados a los pacientes con infección por rotavirus, cuya historia clínica fue revisada, se consideraron al Metronidazol y a los antibióticos (Bactrim y Ampicilina). El 47\% y $12 \%$ de los casos con infección por rotavirus recibieron Metronidazol y antibióticos respectivamente (datos no mostrados).

El análisis de la asociación entre la infección por rotavirus, y factores climáticos, como: temperatura, 


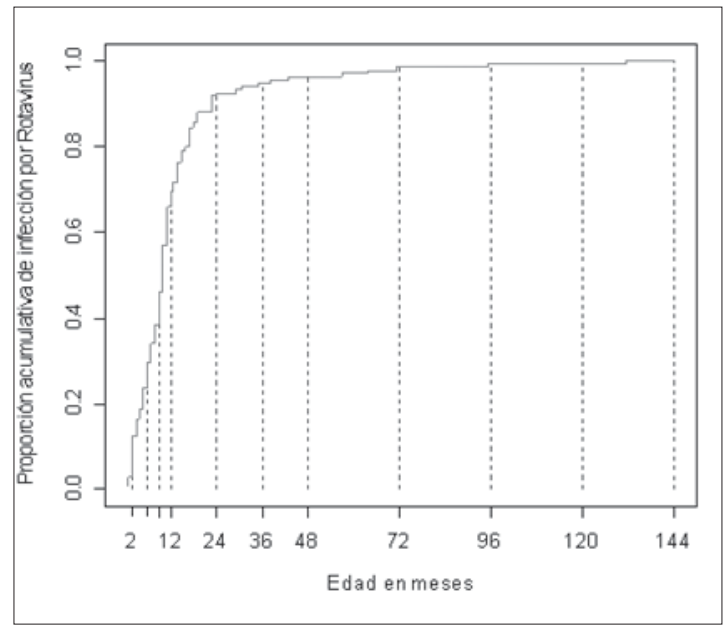

Figura 5. Porcentaje acumulativo de casos de EDA con infección por rotavirus en función a la edad.

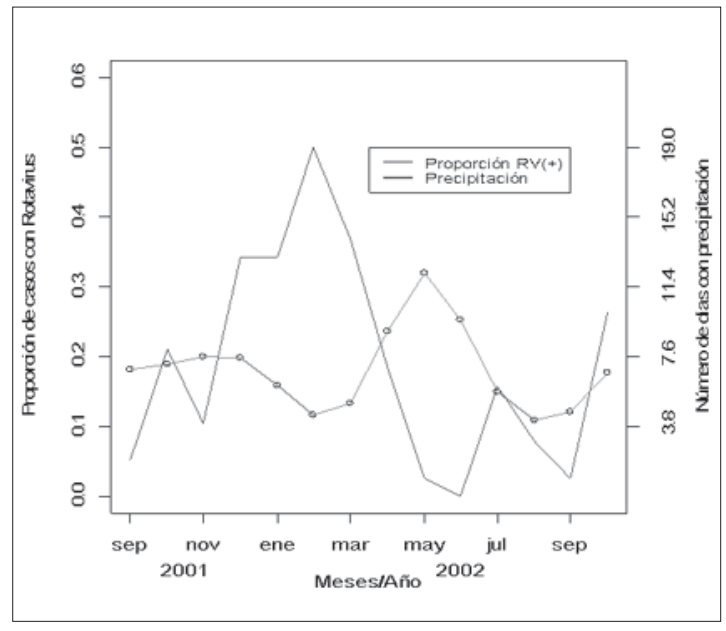

Figura 6. Distribución mensual de casos de rotavirus positivo (rojo) y número de días con precipitación, registrada durante el período 2001-2002.

Tabla 2. Manifestaciones clínicas, ${ }^{*}$ relacionadas a la diarrea por rotavirus. Porcentajes de sensibilidad, especificidad, valor predictivo positivo (VPP) y valor predictivo negativo (VPN)

\begin{tabular}{|c|c|c|c|c|c|c|}
\hline $\begin{array}{l}\text { Manifestaciones } \\
\text { Clínicas }\end{array}$ & $\begin{array}{c}\text { Sensibilidad } \\
\text { n }(\%)\end{array}$ & $\begin{array}{c}\text { Especificidad } \\
\text { n }(\%)\end{array}$ & $\begin{array}{c}\text { VPP } \\
\text { n } \quad(\%)\end{array}$ & $\begin{array}{c}\text { VPN } \\
\text { n } \quad(\%)\end{array}$ & $\chi^{2}$ & Valor de $p$ \\
\hline Desh. Moderada & $46 \quad(66)$ & $186(83)$ & $46 \quad(83)$ & $186(94)$ & 76,29 & $2,2 * 10^{-16}$ \\
\hline Desh. Leve & $18(62)$ & $186(83)$ & 18 (33) & $186(94)$ & 76,29 & $2,2 * 10^{-16}$ \\
\hline Vómito & 69 (45) & $157(80)$ & 69 (64) & $157(65)$ & 24,36 & 0,0000008 \\
\hline Fiebre & $57 \quad(43)$ & $169(76)$ & $57 \quad(53)$ & $169(70)$ & 14,04 & 0,00017 \\
\hline
\end{tabular}

VPP (valor predictivo positivo); VPN (valor predictivo negativo). * Los datos fueron recolectados a partir del $31 \%$ y $27 \%$ de historias clínicas de pacientes ambulatorios y hospitalizados respectivamente.

humedad relativa y número de días con precipitación, mostró que los picos más altos de infección del virus, correlacionan con la época, donde se registró menor número de días con precipitación (figura 6), observándose una correlación significativa mediante un análisis de regresión logística $(\mathrm{p}=0,00265)$.

A partir de 65 muestras de RNAde de rotavirus, que presentaron concentraciones optimas para el análisis de RT-PCR, el 70\% (46) de las muestras analizadas presentaron al menos uno de los genotipos ( $\mathrm{G}$ o $\mathrm{P}$ ). El 30\% restante corresponde a muestras no-tipeables (tabla 4). Los genotipos G encontrados fueron G1 (44\%) y G2 (6\%). Entre los genotipos P, se encontraron, $\mathrm{P}[8]$ (24\%) y $\mathrm{P}[6]$ (15\%). Las combinaciones de genotipos $\mathrm{G}$ y $\mathrm{P}$ caracterizadas fueron G1P[8] (14\%), G1P[6] (6\%) y G1P[8]P[6] $(1,5 \%)$ (tabla 4). En tres muestras, se observo una coinfección entre P[8] y P[6] (4\%). Asimismo se observó un alto porcentaje de cepas no-tipeables tanto para genotipos G (49\%) como $\mathrm{P}(55 \%)$.

$\mathrm{El}$ análisis de los genotipos $\mathrm{G}$ y $\mathrm{P}$ en relación a la procedencia de las muestras, mostró que [P6] esta significativamente asociado a muestras ambulatorias $\left(\chi_{2}^{2}=4,9156 ; \mathrm{p}=0,0856\right)$ (tabla 5). 
Tabla 3. Diarrea por rotavirus: Enfermedades intercurrentes, infecciones y deficiencia alimentaría

\begin{tabular}{|c|c|c|c|c|c|}
\hline \multicolumn{6}{|c|}{ Rotavirus } \\
\hline & \multicolumn{2}{|c|}{$(+)$} & $(-)$ & \multirow{2}{*}{$\frac{\chi^{2}}{11,36}$} & \multirow{2}{*}{$\begin{array}{l}\text { valor } \mathbf{p} \\
0,00074\end{array}$} \\
\hline \multirow{2}{*}{$\begin{array}{l}\text { Amebas-parásitos } \\
\text { IRA }\end{array}$} & 22 & $(22 \%)$ & $(43 \%)$ & & \\
\hline & 15 & $(15 \%)$ & $(8 \%)$ & 2,24 & 0,1343 \\
\hline Anemias & 25 & $(25 \%)$ & $(16 \%)$ & 2,99 & 0,0873 \\
\hline
\end{tabular}

Tabla 4. Distribución de los genotipos G y P y combinaciones genotípicas de cepas de rotavirus circulantes

\begin{tabular}{lccccc}
\hline $\begin{array}{l}\text { Genotipo } \\
\text { G/P }\end{array}$ & \multicolumn{2}{c}{ Número de casos con genotipo P } \\
P[8] & P[6] & P[8]P[6] & No-tipeable & Total \\
\hline G1 & 9 & 6 & 1 & 13 & 29 \\
G2 & 0 & 0 & 0 & 4 & 4 \\
No-tipeable & 7 & 4 & 2 & 19 & 32 \\
Total & 16 & 10 & 3 & 36 & 65 \\
\hline
\end{tabular}

Tabla 5. Distribución de genotipos G y P de cepas de rotavirus circulantes, en pacientes hospitalizados y ambulatorios

\begin{tabular}{rrrrrrrrrr}
\hline & $\mathbf{n}$ & \% & A & H & & n & \% & A & H \\
\hline G1 & 28 & 87 & 15 & 13 & P [8] & 15 & 53 & 8 & 7 \\
G2 & 4 & 12 & 3 & 1 & P[6] & 10 & 10 & 10 & 1 \\
Total & 32 & 100 & 18 & 14 & Total & 28 & 100 & 18 & 10 \\
\hline
\end{tabular}

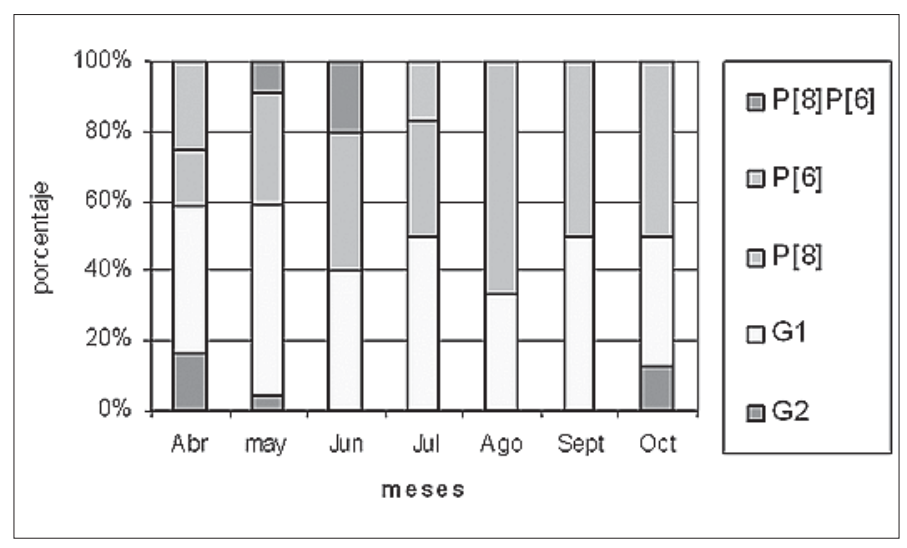

Figura 7. Distribución de los genotipos de rotavirus G y P a lo largo de 7 meses.
A su vez, el análisis de la distribución de los genotipos $\mathrm{G}$ y $\mathrm{P}$ a lo largo de 7 meses de estudio (figura 7), mostró que G1 al igual que el genotipo [P8], están presentes en todos los meses. El genotipo G2 se observó en los meses de abril, mayo y octubre. El genotipo P[6] en los meses de abril, julio, septiembre y octubre, y la coinfección $\mathrm{P}[8] \mathrm{P}[6]$ en los meses de mayo y junio, que coincide con los meses donde se registran los porcentajes más altos de infección por Rotavirus. 


\section{Discusión}

En Latinoamérica la diarrea rotaviral es una de las causas más comunes de hospitalizaciones y visitas médicas. Datos reportados a partir de 28 estudios realizados en pacientes hospitalizados y ambulatorios en niños de diferentes países de Latinoamérica, muestran que las gastroenteritis causadas por rotavirus son responsables de un $16 \%$ a un $52 \%$ de los casos ${ }^{18}$. En el presente estudio, en la ciudad de Cochabamba, se encontró un 19\% de prevalencia de la diarrea rotaviral.

En Bolivia estudios realizados en el Instituto de Biología Molecular y Biotecnología (IBMB) en las ciudades de La Paz y el Alto, en niños menores a 5 años con diarrea, han reportado datos de la prevalencia del virus ${ }^{19-22}$ que alcanza alrededor de $25 \%$.

Varios estudios ${ }^{23-25}$, además muestran que el rotavirus esta más asociado a los casos de gastroenteritis aguda que requieren hospitalización. En este trabajo, se observa claramente este patrón, ya que el porcentaje de infecciones por rotavirus en pacientes hospitalizados es en un $7 \%$ mayor que en pacientes ambulatorios. Dado que el número de muestras analizadas de pacientes ambulatorios es mayor al reportado en otros estudios realizados en Bolivia ${ }^{20-22}$, estos datos confirmarían el efecto de la severidad de la diarrea rotaviral, lo que implicaría que la introducción de una vacuna tendría un impacto positivo en nuestro medio.

El análisis de los porcentajes mensuales de EDA registrados durante el año de estudio en el Hospital Albina Patiño mostró dos picos de incidencia (figura 3). Un brote coincide con los meses de verano, al cual se le podría atribuir, a las infecciones causadas por bacterias y parásitos. El otro pico se registro en los meses más fríos, donde se observa la mayor incidencia de infección por rotavirus. Sin embargo, es importante señalar que el rotavirus esta también presente en verano, en los meses correspondientes a noviembre (19\%), diciembre $(27 \%)$ y enero (17\%), los cuales coinciden con el brote de EDA registrado en esa época (figura 3 ).

Por lo tanto se destaca la importancia del rotavirus como causa de gastroenteritis, a lo largo de todo el año.
Los rotavirus tienen generalmente una prevalencia estacional de infección, con picos epidémicos en los meses fríos y secos de cada año, este patrón estacional es observado en países de climas, templados y no así en otros países con clima tropical ${ }^{8,26,27}$. Estudios realizados en Asunción-Paraguay ${ }^{28}$, Córdova-Argentina, Mina-Giráis-Brasil ${ }^{25}$, se observa un pico de incidencia de la infección por rotavirus durante los meses más fríos y secos del año. Sin embargo, en la mayoría de los estados de la región norte de Brasil, con clima tropical, no se observa un patrón estacional definido ${ }^{29}$. La Ciudad de Cochabamba es un valle, con clima templado de invierno seco con presencia de precipitaciones pluviales a lo largo del año que coinciden con los meses más calientes, con una temperatura promedio que oscila entre $13^{\circ} \mathrm{C}$ $22^{\circ} \mathrm{C}$. Al parecer las temperaturas bajas y la poca humedad contribuyen a la mejor sobrevivencia del rotavirus en la naturaleza. Comparando con la prevalencia estacional del rotavirus registrada en la ciudad de La Paz, se observa una similar correlación entre el brote mayor de infección por rotavirus y los parámetros climáticos, a pesar de las diferencias topográficas y climáticas entre ambas ciudades Esto podría deberse a la estacionalidad marcada del invierno y verano en ambas ciudades. Otros estudios en departamentos como Santa Cruz y Beni deberán confirmar a nivel nacional, estas observaciones.

La gastroenteritis infecciosa severa causada por rotavirus ocurre más frecuentemente en niños de 6 a 24 meses de edad y requiere en muchos casos de hospitalización ${ }^{8}$. En este estudio, se observó que el 92\% de pacientes hospitalizados, con infección por rotavirus, comprende a niños entre 3-24 meses de edad. Los porcentajes más bajos de prevalencia se observaron en pacientes menores a 2 y mayores a 24 meses. En pacientes ambulatorios, se observó que el grupo etáreo entre 7 y 12 meses presentó un $31,2 \%$ de infección por rotavirus, similar valor (33\%) se observó en los niños menores a 2 meses y podría deberse al bajo número de casos registrados en este grupo etáreo. La mayoría de los estudios, reportan bajos porcentajes de infección por rotavirus en los primeros meses de edad. En un estudio en el norte de 
Ghana, se observó que el número de episodios diarreicos por rotavirus incrementa con la edad, observándose en los primeros 2 meses un 5\% de episodios diarreicos por rotavirus.

En conjunto, los datos del presente trabajo, tanto de pacientes hospitalizados como ambulatorios, indicarían que el grupo etáreo más vulnerable a la diarrea rotaviral, comprende a niños entre 3-24 meses de edad (88\%).

Las infecciones por rotavirus, se caracterizan porque están asociadas con síntomas clínicos característicos, como diarreas liquidas, fiebre, vómitos, siendo estos los síntomas más prominentes durante los primeros días de la enfermedad ${ }^{30}$. En este estudio, del total de historias clínicas revisadas de pacientes con EDA, más del $50 \%$ de los casos que presentaron infección por rotavirus, mostraron una correlación estadísticamente significativa con los síntomas clínicos más característicos, como vómitos, fiebre y deshidratación. La severidad de la diarrea por rotavirus esta fundamentalmente asociada a la deshidratación, siendo esta una de las principales causas de hospitalización y refleja la necesidad de la introducción de medidas preventivas.

Entre los datos que resaltan del análisis clínico es el porcentaje $(22 \%)$ de las diarreas causadas por rotavirus que están relacionadas con la presencia de amebas y parásitos. Esto probablemente se deba a que las infecciones por amebas y parásitos sean endémicas en la ciudad de Cochabamba. Generalmente en otros estudios no se ha observado coinfecciones de rotavirus y parásitos ${ }^{31}$.

Las muestras de RNA viral, fueron tipificadas mediante la técnica de RT-PCR que permitió determinar la diversidad de genotipos $\mathrm{G}$ y $\mathrm{P}$ en una muestra representativa, la cual abarcó a 7 meses de estudio. Entre los genotipos encontrados, por un lado G1, G2 y por otro $\mathrm{P}[8],[\mathrm{P} 6]$ son considerados los más comunes. Esto coincide con un estudio de vigilancia epidemiológica ${ }^{32}$ a partir de 15 estudios realizados en 5 países de Latinoamérica, que muestran la prevalencia de las cepas G1P $[8](40,1 \%)$, G2[P4] (29,4\%), G3[P8] (6,1\%).

Las cepas G1 y P[8] se presentaron a lo largo de los meses analizados, mientras que G2 se presentó de forma esporádica, contrario a lo que se observa en otras regiones, como Australia, donde la distribución de G2 es constante a lo largo del año ${ }^{33}$. La única coinfección observada $\mathrm{P}[8] \mathrm{P}[6]$ se presento durante el brote de prevalencia más alto de infección por rotavirus, que coincide con los meses más fríos y secos, esto indicaría que en esta época existe un mayor número de cepas circulantes.

En este trabajo no se testaron a otros genotipos $\mathrm{G}$ y $\mathrm{P}$ emergentes por lo que futuros estudios deberán considerar no sólo un mayor número de muestras para la genotipificación, sino también el análisis de muestras no-tipeables $(30 \%)$.

En conjunto los datos de distribución de genotipos $\mathrm{G}$ y $\mathrm{P}$ encontrados, permiten inferir que cualquiera de las dos vacunas antirotavirales vigentes potencialmente, brindarían protección contra las cepas circulantes encontradas en la ciudad de Cochabamba, por lo que será importante precisar a corto plazo estimaciones de la carga de la diarrea rotaviral y el impacto potencial de una vacuna antirotavirus.

\section{Agradecimientos}

Agradecemos al Dr. Carlos Terán responsable del departamento de investigación del hospital pediátrico Albina Patiño y a su personal de laboratorio y administrativo. A la Dra. Shirley Aramayo y al Señor Natalio Medrano por la colaboración prestada. A los Dres. Roger Glass y Jon Genstch de la Unidad de Gastroenteritis Viral del CDC-Atlanta, por el apoyo generoso en la provisión de reactivos.

\section{Referencias}

1.- Kosek M, Bern C, Guerrant RL: The Global burden of diarrhoeal disease, as estimated from studies published between 1992-2000. Bull World Health Organ 2003; 81: 197-204.

2.- Organización Mundial de La Salud (OMS). Sitio web del departamento de Salud y desarrollo del niño y el adolescente (http://www.who.int/child-adolescenthealth) 2003.

3.- Servicio Nacional de Información en Salud (SNIS). sitio web http://www.sns.gov.bo. 2002.

4.- Glass RI, Lang DR, Ivanoff BN, Compans RW: Introduction: Rotavirus-from Basic Research to a 
Vaccine. J Infect Dis 1996; 174: 1-2.

5.- Parashar UD, Hummelman EG, Joseph S, Miller MA, Glass RI: Global Illness and Deaths Caused by Rotavirus Disease in Children. Emerg Infect Dis 2003; 9: 56571.

6.- Estes $M K$ : Rotavirus Gene Structure and Function. J Clin Microbiol 1989; 53: 410-49.

7.- Gentsch JR, Glass RI, Woods P: Identification of Group A Rotavirus Gene 4 Types by Polymerase Chain Reaction. J Clin Microbiol 1992; 30: 1365-73.

8.- Kapikian AZ, Hoshino Y, Chanock RM: Rotaviruses. In Fields Virology 2001; 2: 1787.

9.- Rao CD, Gowda K, Reddy BS: Sequence analysis of VP4 and VP7 genes of non-typeable strains identifies a new pair of outer capsid proteins representing novel $\mathrm{P}$ and $\mathrm{G}$ genotypes in bovine rotaviruses. Virol 2000; 276: 104-13.

10.- Coulson BS, Gentch JR, Das BK, Bhan MK, Glass RI: Comparison of Enzime Immunoassay and Reverse Transcriptase PCR for Identification of Serotype G9 Rotaviruses. J Clin Microbiol 1999; 37: 3187-93.

11.- Maunula L, Von Bonsdorff CH: Short Sequences Deline Genetic Lineages: Phylogenetic Analysis of Group A Rotavirus Based on Partial Sequences of Genome Segments 4 and 9. J Clin Microbiol 1998; 37: 1699703.

12.- Gentsch JR, Glass RI, Woods PA, et al: Review of G and $\mathrm{P}$ typing results from a global collection of rotavirus strains: Implications for vaccine development. J Infect Dis 1996; 174: 30-6.

13.- Herring AJ, Ingliss CK, Snodgrass DR, Menzies JD: Rapid Diagnosis of Rotavirus Infection by Direct Detection of Viral Nucleic Acid in Silver-Stained Poliacrylamide gels. J Clin Microbiol 1982; 38: 898901.

14.- Santos N, Gouvea $V$ : Improved method for purification of viral RNA from fecal specimens for Rotavirus detection. J Virol Methods 1994; 46: 11-21.

15.- Gouvea V, Glass RI, Woods P, et al: Polymerase Chain Reaction Amplification, and Typing of Rotavirus Nucleic Acid from Stool Specimens. J Clin Microbiol 1990; 28: 276-82.

16.- Gouvea V, Santos N, Timenetsky MC: VP4 Typing of Bovine and Porcine Group a rotaviruses by PCR. J Clin Microbiol 1994; 32: 1333-7.

17.- $\mathrm{R}$ Development Core Team a language and environment for statistical computing. R Foundation for Statistical Computing. 2005 Vienna, Austria. http:// www.R-project.org

18.- Kane M, Turcios R, Arvay M, García S, Bresee J, Glass J: The Epidemiology of Rotavirus Diarrhea in Latin America Anticipating Rotavirus Vaccine. Pan Am J Public Health 2004; 16: 371-7.

19.- Arias JL: Gastroenteritis infantil por Rotavirus. Tesis de Licenciatura. Facultad de Ciencias Puras. UMSA, La Paz-Bolivia.1988.

20.- Mamani N: Epidemiología Molecular de la diarrea rotaviral en humanos. Tesis de Licenciatura. Facultad de Ciencias Puras. UMSA, La Paz-Bolivia. 1995.

21.- Millares $J$ : Rotavirus Humano y Animal: Algunos aspectos epidemiológicos y variabilidad genética. Tesis de Licenciatura. Facultad de Ciencias Puras. UMSA, La Paz-Bolivia. 1993.

22.- Encinas A: Prevalencia y Caracterización molecular de cepas de Rotavirus en niños menores a 5 años en las ciudades de La Paz y el Alto agosto 2001 a diciembre 2002. Tesis de Maestría. Maestría de Ciencias Biológicas y Biomédicas. UMSA, La Paz-Bolivia. 2005.

23.- Cunliffe NA, Dove W, Bunn JEG, et al: Expanding Global Distribution Serotype G9: Detection in Libya, and Cuba. J Clin Microbiol 1996: 1-10.

24.- Cardoso DP, Soares CMA, Souza MB, et al: Epidemiological Features of Rotavirus Infections in Goiania, Goias, Brazil, from 1986 to 2000. Mem Inst Oswaldo Cruz 2003; 98: 25-9.

25.- Rosa E, Silva M: Epidemiological Aspects of Rotavirus Infections in Minas-Gerais, Brazil. J Infect Dis 2001; 5: 215-22.

26.- Ho MS, Glass RI, Pinsky PF, Anderson LJ: Rotavirus as a cause of diarrheal morbidity and mortality in the United States. J Infect Dis 1988; 158: 1112-6.

27.- O'Ryan M, Mamani N, Avendano LF, et al: Molecular epidemiology of human rotaviruses in Santiago, Chile. Pediatr Infect Dis 1997; 16: 305-11.

28.- Coluchi N, Munford V, Manzur J, et al: Detection, Subgroup Specificity and Genotype Diversity of Rotavirus Strains in Children With Acute Diarrhea in Paraguay. J Clin Microbiol 2002; 40: 1709-14.

29.- Pereira HG, Linhares AC, Candeias JAN, Glass RI: National Laboratory surveillance of viral agents of gastroenteritis in Brazil. Bull Pan Am Health Organ 1993; 27: 224-33.

30.- Armero JA, Clara W, Turcios R, Chacón R. Valencia D, Sandoval R, Figueroa J, Bresee J, Glass RI: Brote vigilancia y estimaciones de la carga del enfermedad 2000-2002. Pediatr Infect Dis J 2004; 23: 14-8.

31.- Hernández FM., Camacho CG, Contreras SV, Mercado JC, Arias CF: Pronóstico de la Diarrea por Rotavirus. Rev Salud Pública Méx 2001; 43: 524-8.

32.- Castello A, Arvay M, Glass RI, Gentsch J: Vigilancia de cepas de Rotavirus en Latinoamérica Revisión de los últimos nueve años. Pediatr Infect Dis J 2004; 23 : 26-30.

33.- Bishop RF, Masendycz PJ, Bugg HC, Carlin JB, Barnes GL: Epidemiological Patterns of Rotaviruses Causing Severe Gastroenteritis in Young Children throughout Australia from 1993-1996 J Clin Microbiol 2001; 39: 1085-91. 